\title{
The Scenario-Based Verification Method of the Buildings' Energy Balance: The Analyzed Parameters and Implementation Algorithm
}

\author{
VolkovAndrey $^{1}$, ChelyshkovPavel ${ }^{2}$, SedovArtem $^{3}$
}

${ }^{1}$ DSc, prof., Rector of MSUCE Russia, Moscow, Moscow state university of civil engineering, Yaroslavskoeshosse 26

${ }^{2}$ Ph.D., Head of the Information Systems in Construction Laboratory Russia, Moscow, Moscow state university of civil engineering, Yaroslavskoeshosse 26

${ }^{3}$ Ph.D., Head of the Intelligent Systems Laboratory Russia, Moscow, Moscow state university of civil engineering, Yaroslavskoeshosse 26

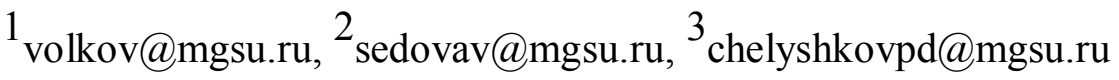

Key words: energy and environmental modeling;power efficient buildings and structures.

Abstract: This article was performed within the Russian State tasks MSUCE project "Methodology of ideas, design and verification of energy-efficient engineering systems conventionally abstract objects (on formal models of buildings)". The article describes the algorithm verification scenario of the energy balance of buildings.

\section{Introduction}

Currently, more than $40 \%$ of the energy produced is consumed engineering systems in residential buildings. In terms of ongoing commissioning of residential homes there is an issue of energy scarcity and, therefore, there is a need to determine the energy balance - energy consumption - existing and newly constructed buildings with the aim of coordinating the energy resources' allocation and the planning of new generation capacities. Additionally, objective analytical estimation of the energy balance of buildings and complexes significantly speeds up the process of decision making in the housing tariff policy.

It is very important at the design stage to assess resource consumption buildings and complexes in the operation process in modern energy resources' scarcity conditions.

It is necessary to take into account the environmental conditions' heterogeneity, the inability to describe one set of parameters for all possible modes of facility operation.

The consideration of dynamic effects on the various external factors' combinations object gives the scenario modeling. Using a mathematical model engineering systems such as modeling in CAD conducts verification engineering solutions for buildings and complexes in a wide range of external influences. 


\section{Discussion}

The proposed method scenario verification of the buildings' and complexes' energy balance allows predictingthe consumption of thermal and electric energy buildings and complexes for various purposes and with different composition of engineering systems. Forecasting is carried out by computer different scenarios simulation of buildings and complexes engineering systems operation on the mathematical model of power engineering systems of buildings and complexes.

The scenario-based verification of the buildings' and complexes' energy balance method allows taking into account forecasting the following factors, which have different degrees of impact on energy consumption:

1. Weather conditions: outside air temperature; relative humidity; surface density of the heat flow through the glass of the light aperture from direct solar radiation; surface density of the heat flow through the glass of the light from the doorway diffuse solar radiation;

2. the Influence of human activity in the building: the number of people in the room; heat and moisture from people (depending on the nature of the activity); the number and capacity of operating personal computers; the number and power of the working printing devices (printers); the number and power of the working units of special equipment; the number and power of the working of lighting devices;

3. Requirements for microclimate parameters: supported internal air temperature; supported relative the inside air humidity;

4. Characteristics walling: the square and the above heat resistance of external walls (excluding openings); the square and the reduced heat resistance external doors and gates; the square and reduced heat resistance combined coatings (including bay windows); the square and reduced heat resistance of attic floor; area and ground floor reduced heat resistance; the area and reduced heat resistance of floors above passages and under bay windows; the square of translucent structures; the reduced heat resistance glass of fenestration; ratio of window openings light transmission;

5. theparameters of engineering systems: time amount of supply air when the ventilation in use; the time volume of exhaust air using exhaust ventilation; temperature of the coolant; the pressure in hydraulic systems; characteristics of the heat exchangers when using recovery; the percentage of fresh air when using recirculation ventilation and air heating; equipment characteristics (efficiency motors, refrigeration coefficients of refrigerating machines etc.).

The building is treated as a set of types of premises. The types of premises distinguished by the following indicators: number of employees personal computers, 
the number of employees printing devices (printers); number of working units of special equipment; the number of working lighting; power working personal computer; the power of the working printing devices (printers); the power of the working units of special equipment (under special equipment means equipment, machines and mechanisms, which cannot be attributed to the listed categories); the power of the working of lighting devices; maintain the internal air temperature; supported relative humidity of the inside air; the material of external walls (excluding openings); material external doors and gates; material combined coatings (including bay windows); material attic floors; ground floor; material overlaps over passages and under bay windows; the type of translucent structures; and the composition of the utility systems serving the premises. Accordingly, the number of cycles of input data is equal to the number of types of premises.

When automatically calculating the thermal parameters walling used database provides resistance to heat transfer of different types of walling, provides resistance to heat transfer of various types of glazing and coefficients heat transfer different types of glazing window openings.

Modeling weather conditions could be performed in two ways: either to model arbitrary user-defined values of weather conditions, or as simulation of the real weather conditions in 2008, on the basis of archival data.

The automatically generated scripts include the parameters of human influence on the energy balance: the number of people who stay in rooms of different types, the nature of their practice. To script using a database specific heat and person's moisture, depending on the practice and the ambient temperature nature.Consider four character classes: holiday, easy work, moderate and hard work. The scenarios take into account the expert assessment of the probability of a certain number of people and different character classes.

Computer simulation of heat and elegctric energy is carried out on the mathematical model. The model includes 15 modules corresponding to various buildings' engineering systems. Thus, in particular, the module radiator heating module system natural ventilation, module air conditioning systems,supply air, etc. This set of modules is possible to simulate the engineering systems' functioning and ninety-two types of buildings and complexes as in cold and warm periods of the year.

The initial data for the simulation are: composition used in the studied building engineering systems; modeling; permanent features of the building and engineering systems; the variables of weather conditions and human influence, with different values corresponding to different scenarios.

The simulation result is the values of thermal and electrical energy consumption data of a building for a certain period under the influence of the factors provided by the scenarios. 
Thus, the purpose of the method with high reliability is to determine the necessary amount of thermal and electrical energy required engineering systems of a building for an arbitrarily set period of time to maintain the established parameters of the microclimate (temperature and relative humidity) under non-stationary loads.

\section{References:}

1. A.A. Volkov Stability in the formalization of the functional management of technical systems in the building. Collected papers of XI international interuniversity scientific.-practical use. proc. "Construction is the formation of living environment". - M.: ASV, 2008. - p. 274-279.

2. A.A. Volkov, P.D. Chelishchev Methods of the theory of probabilities in the scenario simulation of buildings and complexes in CAD Scientific and technical journal Vestnik MGSU. Issue 6. 2011 Periodic scientific publication. M: MSSU, 2011

3. P.D. Chelishchev Modeling perspective of energy consumption in CAD engineering systems of buildings and complexes. Proceedings of the International scientific conference "Integration, partnership and innovation in building science and education". M: MSSU, 2011.

4. Doroshenko S.A., Doroshenko A.V. Physical Modeling of Flow around the Underwater Tidal Power// Procedia Engineering, Volume 91, 2014, Pages 194199

5. Varapaev V.N., Doroshenko A.V. Methodology for the Prediction and the Assessment of Pedestrian Wind Environment around Buildings // Procedia Engineering, Volume 91, 2014, Pages 200-203 